\title{
OS MOMENTOS INTERPRETATIVOS DA ANTROPOLOGIA \\ E A ANTROPOLOGIA VISUAL COMPARTILHADA ${ }^{1}$
}

Gabriel O. Alvarez ${ }^{2}$

\section{Hermenêutica e método na Antropologia. Os momentos interpretativos da Antropologia}

Roberto Cardoso de Oliveira (1928-2006) foi um dos antropólogos mais destacados da sua geração. A finais da década de 1950 realiza suas etnografias com os Terena e os Ticuna, em um trabalho que tem por eixo a crítica à "teoria da aculturação" a partir da "teoria da fricção interétnica". Esta abordagem se centro nas identidades como construção e ideológica e como posição na estrutura social. A análise assinalou a posição subordinada dos indígenas, num sistema interétnico marcado pelo colonialismo interno. Na década de 1980 Cardoso de Oliveira inicia uma guinada hermenêutica, a partir da qual renova a epistemologia nas ciências sociais e produz uma reflexão original acerca dos momentos interpretativos no ofício do antropólogo.

Em O pensamento antropológico, Cardoso de Oliveira (1988), assinalou que a diferença das ciências duras, onde os paradigmas se sucedem no tempo, na antropologia coexistem diversos paradigmas, que coincidem, a grandes traços, com as tradições nacionais na antropologia. Esta obra nos coloca numa perspectiva teórica, na qual as exigências do método positivista são reformuladas pela perspectiva humanista. Assim, as exigências de explicação, ahistoricidade, universalidade, e objetividade, são deslocadas para a compreensão, para um saber historicamente construído, de âmbito regional, local, ou nacional, e o que é mais importante, intersubjetivo. Estas reflexões está registradas também no vídeo realizado com Cardoso de Oliveira, especialmente nas reflexões finais sobre antropologia e hermenêutica (Alvarez, 2008).

Por outro lado, se para a ciência positivista a verdade é uma questão de método, nas ciências humanas, como assinalou Gadamer (apud Cardoso de Oliveira in Alvarez 2008, Cardoso de Oliveira, 1998) o método acompanha-se dos momentos não metódicos, serendípicos. Isso não implica uma renuncia ao método, mas o reconhecimento das suas limitações. Uma parte importante dos resultados das pesquisas antropológicas são resultados dos momentos não metódicos, da experiência do antropólogo imerso numa outra tradição cultural.

Cardoso de Oliveira (1998) centrou suas reflexões em três momentos interpretativos do trabalho do antropólogo: quando se realiza o trabalho de campo; no trabalho de gabinete; a

\footnotetext{
1 Trabalho apresentado no GT 44 - De lo crudo a lo cocido III. Investigaciones audiovisuales y proyectos de documentales antropológicos, durante o X Congresso Argentino de Antropología Social, La antropologia Interpelada: nuevas configuraciones político-culturales em América Latina, 29 de noviembre a 2 de diciembre de 2011. Versão preliminar, não citar sem autorização expressa do autor.

${ }^{2}$ Universidade Federal de Goiás, Brasil.
} 
publicação da monografia. Em este trabalho interpelamos este esquema a partir dos princípios rouchianos, da realização de uma antropologia compartilhada a partir da filmagem participante, da edição compartilhada e da publicação do material monográfico e audiovisual.

O primeiro momento interpretativo, o trabalho de campo, está marcado pelo olhar e ouvir, não como qualidades cognitivas e sim como categorias no interior da tradição antropológica. $\mathrm{O}$ olhar, e um olhar informado, pela teoria antropológica, pela formação acadêmica, em tanto que o ouvir é orientado pelo objetivo antropológico de alcançar uma fusão de horizontes de comunicação. Este ouvir, não é um ouvir passivo, pelo contrario está animado pela dialógica, e privilegia a dimensão discursiva, e a criação de uma comunidade de argumentação entre o antropólogo e os nativos. Este modelo privilegia o campo discursivo, e a comunicação racional. Cabe destacar que durante o trabalho de campo, o antropólogo participa da vida social do grupo e conhece tanto pela via metódica, como pelos momentos não metódicos. O conhecimento do antropólogo está ancorado na experiência, na empatia, e tem um componente emotivo (Cardoso de Oliveira, 1998).

O modelo da comunidade de comunicação de Apel (1985), aparece como suposto da comunicação racional, que enfatiza a função referencial da linguagem. No trabalho de campo, quando nos defrontamos com uma tradição cultural diferente, muitas vezes essa referencialidade não se aplica, ou como aponta Cardoso de Oliveira, devemos procurar a fusão de horizontes de comunicação para comprender o Outro, numa perspectiva gadameriana. Em outras ocasiões, a dimensão comunicacional é mais complexa, como na comunicação comunicação ritual, com seus símbolos que se caraterizam por ser polivocais, polisémicos e pela polarização de sentidos (Turner, 2005). Em estes casos compreender uma outra tradição cultural implica compreender e traduzir seus símbolos, para poder aproximar-se do que os hermeneutas chamam de fusão dos horizontes de comunicação.

O segundo momento interpretativo seria o da escrita, quando o antropólogo regressa para seu gabinete e escreve sua monografia. Cardoso de Oliveira (1998) assinala diversos desdobramentos deste momento. Por um lado, o trabalho de biblioteca e o diálogo com os colegas, por outro, a evocação das vivências do campo, que retornam ao lermos nosso caderno de campo. Neste momento, as vivências são "traduzidas" nas claves da tradição antropológica, são ordenadas e apresentadas em forma de texto, de discurso, com uma linearidade. Gostaria acrescentar às observações de Roberto Cardoso de Oliveira a sala de aula como performance, na qual apresentamos e discutimos os resultados das nossas pesquisas com alunos ou quando as apresentamos em palestras ou seminário, nesse momento a dialógica no interior de uma comunidade de comunicação de pesquisadores tem um importante papel na construção do produto final, a monografia. 
O terceiro momento interpretativo é o do leitor frente ao texto, onde não terá mais o autor para aclarar o sentido, ou realizar arguições que auxiliem a compreensão. Neste momento, observava Cardoso de Oliveira (1998), o texto toma vida própria. Nesse momento a antropologia se configura como uma tradução cultural, ao levar ao leitor à experiência do antropólogo, na forma de uma narrativa. Mas a antropologia não é só uma narrativa. Na perspectiva de Cardoso de Oliveira, a antropologia é uma tradição, plural.

Podemos perguntar-nos se a antropologia visual poderia ser considerada uma tradição dentro da antropologia social, assim como os diversos paradigmas. Responder exaustivamente esta questão nos desviaria dos objetivos deste trabalho, mas cabe assinalar que a primeira expedição antropológica, a Expedição ao Estreito de Torres, realizadas dois anos depois da criação do cinema, levou uma filmadora com a qual registrou as danças destes nativos da polinésia. Na primeira expedição ao Estreito de Torres, foi Hadon, quem realizou fotografias dos nativos. A fotografia como método de registro também foi usada profusamente por Malinowsk, cujo arquivo com mais de 1.000 fotografias está disponível online ${ }^{3}$, assim como Evans-Pritchard, com milhares de fotografias dos povos com os que trabalhou na África ${ }^{4}$ (veasé também Pinei 1996, Samain Etiene 1995). Analisar as diversas tradições na antropologia visual transcende os propositos deste trabalho, pelo que focalizaremos o mesmo num autor chave na tradição francesa de antropologia visual: Jean Rouch.

\section{Antropologia visual como antropologia compartilhada}

A fotografia, o registro em vídeo, pode ser empregado para ilustrar os resultados de uma pesquisa, mas também podem ser empregados como uma ferramenta de pesquisa, utilizada para mediar a relação com o grupo. Quando falamos de Antropologia Visual, nos referimos à segunda possibilidade, a do uso do vídeo como um dos métodos a serem utilizados pelo antropólogo no trabalho de campo.

\footnotetext{
3 Acervo de fotos de Malinowski está disponivel no site da LSE http://archives.lse.ac.uk/TreeBrowse.aspx?src=CalmView.Catalog\&field=RefNo\&key=MALINOWSKI\%2F3 consultado no 20/06/2011.

4 Acervo de fotos de Evans-Pritchard está disponível no site do Museu Pitt Rivers http://southernsudan.prm.ox.ac.uk/quick search.php?q=evans+pritchard\&db_choice=photos\&go=search consultado no $20 / 06 / 2011$.
} 
A proposta de uma antropologia compartilhada se desprende das realizações de Jean Rouch, assim como de textos e entrevistas do realizador, assim como dos seus comentaristas (Colleyn, 1995; Piault, 2000; Ribeiro, 2007; Rouch, 2000; Zoetl, 2009). Entre os passos metodológicos sugeridos para chegar a este ideal antropológico, se destacam a câmera participante e a edição compartilhada. O produto, o vídeo antropológico, tem vários elementos em comum com as monografias, mas agrega um componente audiovisual que transcende o discurso escrito, diferenciando-se dele no tipo de comunicação.

A observação participante e a câmera. A câmera participante foi a expressão acunhada por Jean Rouch para se referer à estratégia desenvolvida inicialmente por Flaherty (1922) na realização de Nanook. Por câmera participante se refere à dinâmica de apresentar para o grupo o material registrado durante o dia, e favorecer o diálogo acerca do que deve ser filmado, quem deve ser filmado, como, quando, e onde. Ao apresentar o material depois do dia de filmagem, a comunidade, como sujeito coletivo, faz comentários, piadas, expressa seu ponto de vista acerca do material bruto capturado. O grupo recebe um retorno acerca da sua imagem e a imagem de sim que deseja projetar. Neste diálogo, o antropólogo pode favorecer a dimensão dialógica, propiciando uma direção compartilhada. Por outro lado, o grupo incorpora a participação do antropólogo, e outorga-lhe um rol concreto, criar a sua representação audiovisual. A observação torna-se realmente participante a partir de um objetivo compartilhado.

Edição compartilhada. O referente de Rouch na edição foi Vertov, realizador documentalista soviético, quem cruzou as repúblicas soviéticas registrando com o olho magico da câmera, as transformações da revolução rusa (Mossnac, 1928). O "Cinema-Verdade" de Vertov, foi transmutado pela "verdade no cinema" de Rouch. Para Vertov, a edição começa na elaboração do roteiro, continua durante a filmagem, e se realiza no ato da montagem, a edição propriamente dita, para os documentaristas. O tema desta edição na filmagem está vinculado com a filmagem participante. A participação do grupo nestas diferentes faces (roteiro, captação, montagem) é fundamental para dar o caráter participativo à prática da antropologia visual.

A câmera participante se integra no método antropológico, como uma estratégia para a construção de uma realidade dialógica entre o antropólogo e o grupo. Durante o trabalho de campo junto aos Sateré-Mawé, a rutina de apresentar o material gravado ao final da jornada, reunia grande parte do grupo, que lotava a sala e as janelas da pequena casa de tabuas, na aldeia. Piadas feitas nas bordas, nas janelas, eram índices que sugeriam caminhos a serem trilhados. O fascínio das crianças quando viam os mais velhos, contando os mitos na tela da TV era um índice da eficácia da tradição. Durante estas exibições, surgiam sugestões das filmagens que seriam feitas nos próximos dias. Com esta dinâmica o grupo se apropriou tanto do vídeo como ferramenta para construir sua própria 
imagem, como se apropriou do rumo da pesquisa, ao centrar as filmagens no ritual da tucandira, nos seus cantos e suas interpretações. O velho Tuissa Wilson de Oliveira foi um dos mais envolvidos, tanto de um lado da câmera como do outro. Participou do registro dos cantos da Tucandira, fazendo o coro, fundamental neste tipo de cantos; atuou como diretor, indicando quem seria entrevistado, e cuidava inclusive dos problemas de áudio, mandando as crianças não atrapalharem as condições da filmagem. O tuissa conduziu também entrevistas, que revelam informações que não seriam contadas para os brancos em outras épocas.

Os limites entre a câmera participante e a edição compartilhada são tênues. O processo de edição se inicia ao apresentar o material ao grupo. Nesse momento acontece um diálogo coletivo, importante para saber qual material incluir na pesquisa. Este processo que se inicia com a apresentação do material bruto, dá lugar à exibição do material editado a partir de diversos clipes. A exibição dos clipes reunia espontaneamente à comunidade que se acercava para assistir o material, recriando um espacio público comunicacional. As opiniões são expressas das mais diversas formas. A presença ou ausência de interesse era um índice acerca da recepção do material, nos revelavam também os limites dessa interculturalidade construída com o vídeo. A apresentação do material para o grupo permite avaliar a eficácia a partir da performance do público. A performance é uma reflexão coletiva, social (Turner, 1988).

Teve um caso, o do clipe que realizei com o material gravado com a liderança envolvida no projeto de venda do guaraná ao mercado global, que foi exemplar neste tipo de diálogo entre o vídeo e as bordas de um espaço público tradicional. Obadias tinha um discurso bem articulado, crítico do desenvolvimentismo, ancorado no discurso do "mercado justo", um conceito, ou um sistema de ideias alternativo, que viabilizava sua estratégia como articulador entre o grupo e o público consumidor na Europa. Para minha surpresa, quando exibia este material, os Sateré-Mawé apresentavam pouco interesse e muitos deles se dispersavam. A performance mais significativa destas avaliações coletivas, foi quando um dos participantes, desde a borda fez o trocadilho de Obadias por "o bandido". A risa provocada pela piada era um índice de que o discurso (e o dinheiro) não era bem avaliado a partir da tradição Sateré-Mawé.

O vídeo cria uma comunicação complexa, onde as opiniões são socializadas. Outras cenas significativas aconteceram no fechamento da pesquisa. Nesta oportunidade, eu encontrei os tuxauas e lideranças Sateré-Mawé em Manaus e registrei ou encontro desta embaixada com o governador do estado. Retornei para a terra indígena no barco, junto aos tuxauas, professores e agentes de saúde. Aproveitei a viagem, que demorou 48 hs, para apresentar ao grupo os diversos clipes com os que comporia os filmes. O Tuxaua Donato era um dos que faziam parte da linha dura, e tinha-se resistido a gravar seu depoimento para o vídeo quando o visitei na aldeia. Apresentei o material 
esperando uma reação contraria da sua parte. Fiquei surpreendido com a reação do tuxaua. Quando o velho tuxaua enxergou a Renato Athias, lembrando da reunião na terra indígena Sateré-Mawé, a inícios dos anos oitenta, ficou visivelmente emocionado. Quando viu a reprodução da carta, publicada pelo Porantin na época, seus olhos se encheram de lágrimas. Depois de assistir ao vídeo, fez questão de declarar publicamente que esse clipe tinha que ser incluído no filme, porque era o início da luta, o que recebeu a aprovação dos presentes.

Outra atitude, significativa, foi a do Tuxaua Geral, que observava os clipes encostado na varanda do barco, guardando uma certa distância do resto do grupo. Quando terminou a exibição dos clipes, ele me fez chegar um recado, por meio de um professor. Ele tinha "gustado bastante", mas queria agregar uns comentários. Combinamos que acompanharia o tuxaua até Umirituba, onde gravaríamos um depoimento com o tuxaua geral, para fechar o filme. O vídeo introduziu um componente reflexivo na pesquisa.

A montagem compartilhada. A montagem se inicia com a edição dos clips, de pequenas sequências, mais ou menos unitárias, que foram apresentados ao grupo em diversas oportunidades ao longo da pesquisa. A partir destes clipes compomos uma narrativa. Mas, as narrativas audiovisuais podem suportar os mais diversos formatos, como tem demonstrado o cinema. Jean Rouch apresenta um leque que vai do documentário à ficção etnográfica. A montagem deixa em aberto também uma outra questão, de estilo, acerca estrutura da narrativa. A obra de Jean Rouch apresenta diversas alternativas, abrem um leque que inclui o documentário clássico, imbuído de realismo, como em La chasse au Lion à l'arc, (Rouch, 1965); performances, onde os atores apresentam suas vivências, como em Moi um Noir, (Rouch, 1959); até a Ficção Etnográfica, do Petit a Petit, (Rouch, 1965) onde os participantes atuam um roteiro sem pretensões de realismo, mas ao mesmo tempo profundamente antropológico, com uma crítica ao etnocentrismo francês. Alguns dos seus filmes incluem a performance dos participantes dos filmes atuando num pano de fundo antropológico. Outros, como Les Maîtres Fous (Rouch, 1955) se centram em rituais de possessão, estabelecendo uma relação direta entre o realizador e os participantes, uma câmera transe (Stoller, 1994; Sztutman, 2005).

A diferença da escrita da monografia, a edição não acontece necessariamente na solidão do gabinete. A tecnologia digital nos permite realizar a edição num laptop, tanto no campo, como na cidade próxima. No meu caso, grande parte da edição foi realizada no quarto de hotel em Barreirinha, onde com o assistente e parceiro Augusto Sateré, realizamos a tradução do material e discutimos a montagem final. Foi ao abrir e ordenar o material que descobri que tinha registros de diversos cantos, muitos deles apresentados em diversas interpretações. 
Durante a pesquisa elaboramos dois filmes, um deles centrado na tradição o outro na política. Ambos filmes receberam estruturas diferentes. Como representar o ritual no vídeo foi o desafio da montagem do filme da tradição. De uma ou outra forma estrutura do filme replica a estrutura do ritual. Turner analisou o ritual num esquema inspirado em Van Gennep (Gluckman, 1966; Turner, 2005). O ritual poderia ser descrito como um processo que se inicia com a preparação, tem um período liminal, no qual os iniciados são colocados num estado liminal, e o retorno à ordem social. Turner assinalou três níveis de análise para a interpretação dos rituais. Em primeiro lugar, a exegese nativa, as explicações dos participantes, entre a que se destacam os pontos de vista dos diferentes especialistas. Em segundo lugar a observação das relações sociais mobilizadas pelo ritual. Finalmente, a análise do antropólogo a partir da comparação dos diferentes pontos de vista e da sua análise "estrutural" da sociedade. Para Tambiah (1985) o ritual é uma performance em três sentidos: por um lado no sentido de Austin (1990), do poder ilocucionário dos símbolos; no sentido de Leach (1966), como poderoso aparelho comunicacional multimídia; no sentido de Pierce (1986), que nos remete a um terceiro significativo, neste caso a cosmología do grupo (veja-se também Peirano, 2001).

Como representar ou como interpretar o ritual no vídeo. A interpretação se constrói sobre outra interpretação. A edição do filme, 3 Interpretações, (Alvarez, 2009) traz a polissemia do termo interpretação. Interpretação como execução dos cantos, quando eles eram passados na floresta; interpretação como performance, quando eram executados nos rituais; interpretação como exegese, como explicação dos símbolos nos cantos. Por outro lado esta interpretação não houvesse sido possível sem a tradução como interpretação durante a edição compartilhada.

A estrutura do filme combina o momento metódico e não-metódico da antropologia. Esta interpretação é produto dos registros da experiência do campo, com a análise antropológica dos dados. Quando montamos o filme, episódios registrados nas diversas viagens ganham significado ao se integrar numa totalidade. O significado emerge ao final do processo de pesquisa. Cabe assinalar que grande parte do material audiovisual foi captado no primeiro período de trabalho de campo, e que ele veio a fazer sentido ao final do processo de quatro anos de pesquisa. Outra parte do material estava na língua Sateré-Mawé e só depois da tradução ganhou sentido para mim.

A exegese foi importante para interpretar o ritual. Ela nos revelou a estrutura temporal do ritual e o significado das alegorias invocadas nos cantos. O tempo do ritual, esse período liminal, está dividido em três: os tempos da origem, quando os animais eram como gente; o tempo da guerra entre os clãs, do qual resulta a unificação das nações com o nome de Sateré-Mawé, o tempo da cabanagem, a guerra contra o branco. Estes três tempos levam os iniciados num percurso que se inicia nos tempos míticos; passa por um tempo de guerras entre clãs, antes do período colonial; e 
finaliza na guerra contra os brancos, que dominaram os índios pela guerra e pelo comercio. Por outro lado, a análise reflexiva permite observar como os símbolos estão impregnados de uma poética política, que passa do tempo míticos, "em que os bichos eram como a gente”, até os tempos históricos em que os símbolos revelam o etnocídio, a dominação e a dependência econômica do branco.

O símbolo do ritual é a tucandira, a formiga, alegoria da mulher e da guerra. Símbolos rituais são a menor unidade de sentido do ritual e condensam suas características. Turner (2005) assinala como características do símbolo ritual sua polissemia, multivocalidade e polarização de sentidos. Como a metáfora, o símbolo ritual entrelaça sentidos, transforma o obrigatório em desejável e o desejável em obrigatório. Por outro lado, como assinalamos anteriormente, os significados destes símbolos nos remetem à cosmologia do grupo, um horizonte amazônico, tupi.

A exegese do canto de Mypynukuri, apresenta a tucandira como alegoria da mulher. A tucandira representa a mulher mítica, que se desdobra em três qualidades de mulher. Por um lado a mãe do waraná, por outro lado moi, a mulher cobra, o princípio da transformação, e finalmente a terceira mulher é a alegoria da morte, que nos chama desde o fundo da terra. No canto, Mypynukuri, o tatu açu, -que era como gente- aparece como doador de mulheres. Ele tira do fundo da terra a três formigas/mulheres. As cosmologias amazônicas privilegiam a afinidade, com o motivo do doador de mulheres, por contraste com ocidente, onde os mitos de origem privilegiam a consanguinidade, o pai criador (Viveiros Castro, 2002).

Nos cantos do tempo da guerra dos clãs, na exegese do canto da flecha, a formiga representa a guerra. Jogar a formiga no rio é uma metáfora que significa que a guerra vai ser no rio. Na cosmología tupi, os parentes afins são inimigos. Os mitos representam os afins com motivos como o sogro canibal, os tios que matam o sobrinho, e outras representações similares. A guerra entre os clãs culmina na aliança para derrotar o clã dos inimigos canibais. O cassamento como alegoria da aliança é um tema amplamente abordado pela antropologia, presente também nas cosmologias amazônicas.

No canto da época da guerra contra o branco, que remetem à Cabanagem, a alegoria principal é "romper o colar", que significa "mata eles". O colar representa o cerco do branco, um cerco que não era só militar, estava ancorado na dependência econômica, na escravização dos jovens e na prostituição das mulheres. A resposta possível ante este cerco é a guerra. Em este sentido são significativas a imagem de que "jogavam os jovens no rio, amarrados", alegoria que fala dos jovens que iam a estudar à cidade e não retornavam para o grupo, ao serem inseridos em relação serviçal com os brancos. 
Estes tempos míticos se acompanham do ritmo marcado pela performance do ritual. Neste ponto o vídeo é um recurso inigualável para traduzir esse crescendo que dificilmente pode ser referenciado no texto escrito. Os cantos da origem foram interpretados no início da tarde, entre risos e comentários jocosos, por contraste, os cantos da guerra, executados à noite, estavam marcado pelos gritos de dor dos participantes, baixo os efeitos da ferroadas da tucandiras, suando, chorando, em um transe produzido pelo extenuante ritual.

Este vídeo não foi pensado como uma produção autônoma, ele faz parte da obra, que inclui a parte analítica, o olhar antropológico que permite acrescentar sentidos. Podemos falar que o leitor do livro, ao assistir o vídeo tem uma percepção informada pela análise antropológica. É no livro que estão as claves para interpretar o ritual. O capítulo sobre parentesco, quiçá uma das partes mais metódicas da antropologia, é fundamental para interpretar os efeitos ilocucionários do ritual. A partir desta análise é que podemos interpretar o ritual da tucandira como um ritual de casabilidade, um ritual que transforma os afins virtuais em afins efetivos e os inimigos (não-afins) em afins virtuais que podem ser efetivados. A análise revela a polarização de sentidos entre a mulher e a guerra, com o pólos sensorial e ideológico da tucandira como símbolo ritual.

Momento reflexivo, na edição do filme sobre políticas. O segundo filme, Toiro, toiro, toiro, vamos juntos trabalhar" (Alvarez, 2009) foi elaborado seguindo a hipótese de que as lutas pelo reconhecimento tiveram um papel importante na recuperação da autoestima do grupo e na valorização da identidade. Minha hipótese seguiu o caminho mais obvio, focalizando as lutas contra a construção de uma estrada que cortaria a terra indígena e na luta contra a exploração de petróleo na terra indígena realizada pela ELF-Aquitane no início dos anos oitenta. Estes temas foram abordados a partir da evocação dos participantes. Outros dos clipes elaborados para este vídeo continham a campanha do candidato indígena, no ano 2004, e a visita ao governador, realizada pelo candidato indígena e uma embaixada de Tuxauas em 2007. Outros clipes, como o do projeto de etno-desenvolvimento ficaram de fora depois da avaliação coletiva antes mencionada.

Como mencionei anteriormente, o Tuxaua Geral, ao assistir ao material solicitou gravar um depoimento. Para minha surpresa, o Tuxaua Geral assinalou no seu depoimento, que estas lutas tinham sido importantes, mas que a organização indígena, o CGTSM, tinha sido organizado a partir dos problemas enfrentados na área da saúde. Ele assinalou também que os objetivos deste processo político, enxergado como uma marcha, são a saúde, física e espiritual, e a educação das crianças Sateré-Mawé, pois elas são o futuro do povo. Com estas palavras ele assinalou aspectos importantes das políticas sociais, que resultaram numa ampliação da cidadania e que não tinham sido foco desta pesquisa. 
Por outro lado, este episódio e revelador enquanto ao tipo de comunicação estabelecido nesta prática da câmera participante e a edição compartilhada. A discussão audiovisual, do processo de organização política permitiu uma dimensão dialógica, na que os representantes dos grupos, respeitosamente, introduzem suas reflexões acerca do processo, depois da visualização do mesmo por meio dos clipes que comporiam o filme.

Os vídeos acerca da tradição e a política Sateré-Mawé permitiram aprofundar de forma diferente a equação entre a fusão de horizontes e a dialógica. No vídeo do ritual, prevaleceu a fusão de horizontes mediante a análise do ritual, símbolos, para chegar à compreensão dessa dimensão da alteridade indígena. Uno poderia falar de um tempo de longa duração, um processo em que os símbolos do passado constroem a subjetividade das novas gerações. No vídeo da política, prevaleceu a dimensão dialógica, com uma reflexão, implícita e explicita, acerca dos rumos do processo político, numa perspectiva interétnica. Um tempo marcado pelas mudanças e pela ampliação da "cidadania".

Antes de finalizar, um par de reflexões acerca das vantagens e desvantagens desta metodologia. Mencionei anteriormente o caso da tradução como interpretação. Neste ponto, o subtitulado dos filmes revelou que nossos eventuais tradutores realizam uma tradução suja, agregando informações que acham que são relevantes para nossa interpretação e suprimem outras que consideram de pouco interesse ou relevância. O exercício de traduzir frase a frase, para subtitular revelou também que nosso interprete, bilíngue, tinha um vocabulário limitado em português. Depois de vários anos de convívio com a língua e com a cosmologia do grupo, a melhor palavra para as expressões eram produto do diálogo, de sugestões mútuas.

Finalmente, uma das principais limitações do método vem do seu caráter artesanal e compartilhado. Em princípio a produção, artesanal, não terá os padrões hegemônicos de qualidade audiovisual, mas ganhará no componente dialógico, colocando-nos mais perto da antropologia que do cinema, mais perto do olhar nativo que do padrão de "qualidade audiovisual" ocidental.

\section{Referências}

ALVAREZ, Gabriel O. Satereria: Tradição e Política Sateré-Mawê. Manaus: Ed. Valer, 2009. APEL, K-O. La transformación de la filosofia, tomo II. Madrid: Tauros, 1985.

AUSTIN, J. L. Como hacer cosas con palabras: Palabras y acciones. Barcelona: Paidós, 1990.

BAUMAN, Richard. "Verbal Art as Performance". In: American Anthropologist, New Series, v.7, n.2. Arlington: American Anthropological Association, 1975.

CARDOSO DE OLIVEIRA, R. Sobre o pensamento antropológico. Rio de Janeiro: Tempo Brasileiro, 1988. 
CARDOSO DE OLIVEIRA, R. O trabalho do antropólogo, Brasília: Paralelo 15/ São Paulo: UNESP, 1998.

COLLEYN, Jean-Paul. "Entrevista. Jean Rouch, 54 anos sem tripé”. In: Cadernos de Antropologia e Imagem, n.1. Rio de Janeiro: NAI/UERJ, 1995. p. 65-74.

GLUCKMAN, Max. The essays on the ritual of social relations. Manchester: Univ. Press, 1966.

LEACH, Edmund, R. "Ritualization in man in relation to conceptual and social development." In: Philosophical Transactions of the Royal Society of London, Series B, n.772, v.251. London: Royal Society Publishing, 1966. p. 403-408.

LOIZOS, Peter. “A inovação no Filme etnográfico (1955-1985)". In: Cadernos de Antropologia e Imagem, n.1. Rio de Janeiro: NAI/UERJ, 1995. p. 55- 64.

MOUSSNAC, Leon. Lê cinema soviétique. Paris: NRF, 1928. p. 139-221.

PEIRANO, Mariza G. S. O dito e o feito: ensaios de antropologia dos rituais. Rio de Janeiro: Relume-Dumara, 2001.

PIAULT, Marc Henri. Antropologie et cinéma. Paris: Nathan, 2000.

PIERCE, Charles Sander. La Ciencia de La Semiótica. Buenos Aires: Ediciones Nueva Visión, 1986.

PINEI, C. "A história paralela da Antropologia e da fotografia". In: Cadernos de Antropologia e Imagem, n.2. Rio de Janeiro: NAI/UERJ, 1996. p. 29-52.

RIBEIRO, José da Silva. "Jean Rouch, Filme etnográfico e Antropologia Visual". In: Doc On-line, n.03. Covilhã: UBI; Campinas: UNICAMP, 2007. http://www.doc.ubi.pt/03/artigo_jose_ribeiro.pdf. ROUCH, Jean. "O comentário improvisado na imagem. Entrevista com Jean Rouch". In: FRANCE, Claudine de (Org.). Do filme etnográfico à antropologia fílmica. Campinas: Editora da Unicamp, 2000.

SAMMAIN Etienne. "Ver e dizer na Tradição etnográfica: Bronislaw Malinowski e a fotografia". In: Horizontes Antropológicos - Antropologia Visual, n.2. Porto Alegre: PPGAS/ UFRGS, 1995. p. 19-48.

STOLLER, Paul. "Artaud, Rouch, and the cinema of cruelty". In: TAYLOR, Lucien (ed.) Visualizing Theory. Selected essays from V.A.R. 1990-1994. New York, London: Routledge, 1994.

SZTUTMAN, Renato. "Imagens Perigosas: a possessão e a gênese do cinema de Jean Rouch". In: Cadernos de Campo, n.13. São Paulo: USP, 2005. p. 115- 124. http://www.fflch.usp.br/da/cadcampo/ed_ant/revistas_completas/13.pdf.

TAMBIAH, Stanley Jeyara. Culture, Thought, and Social Action: an anthropological perspective. Cambridge: Harvard University Press, 1985

TURNER, Victor Witter. Dramas, fields, and metaphors: Symbolic action in human society. Ithaca: Cornell Univ Press, 1974.

TURNER, Victor Witter. Floresta de Símbolos: Aspectos do ritual Ndembu. Rio de Janeiro: EDUFF, 2005.

TURNER, Victor Witter. From ritual to theatre: The human seriousness of play. New york: Perform Arts Journal, 1982.

TURNER, Victor Witter. Schism and continuity in an African society: A study of ndembu village life. Manchester: Univ Press, 1957.

TURNER, Victor Witter. The Anthropology of performance. New York: Paj Publ., 1988.

TURNER, Victor Witter. The drums of affliction: A study of religious processes among the ndembu of zambia. Oxford: Clarendon, 1972.

VAN VELSEN, J. "A análise situacional e o método de estudo de caso detalhado". In: FELDMAN-BIANCO, B. (Org.). Antropologia das sociedades contemporâneas - Métodos. São Paulo: Global, 1987.

VIVEIROS DE CASTRO, Eduardo. A inconstância da alma selvagem. São Paulo: Cosac \& Naify, 2002. 
ZOETL, Peter Anton. "Braços cortados. O Realismo Fílmico e a Antropologia Visual". In: Iluminuras, Revista Eletrônica do Banco de Imagens e Efeitos Visuais, v.10, n.23. Porto Alegre: BIEV/ UFRGS, 2009. Disponível em: http://www.seer.ufrgs.br/index.php/iluminuras/article/viewFile/10108/5870.

\section{Filmografia}

ALVAREZ, Gabriel O. Os Terena e outros temas. A antropologia de Roberto Cardoso de Oliveira. (DVD) Brasília: ABA, 2008.

ALVAREZ, Gabriel O. “3 Interpretações”. In: ALVAREZ, Satereria. Manaus:Valer, 2009.

ALVAREZ, Gabriel O. "Toiró, toiró, toiró,... vamos juntos trabalhar”. In: ALVAREZ, Satereria, Manaus: Valer, 2009.

BIEV - "O cinema é como uma dança. Entrevista com Jean Arlaud". (DVD) Porto Alegre: Banco de Imagens e efeitos visuais, PPG Antropologia - UFRGS; Paris: Laboratoire d'Anthropologie Visuelle et Sonore Du Monde Contemporain - Université de Paris 7.

VERTOV, Dziga. Kino-Glaz, USSR, 1924, 35mm, b/w, silent film, $70 \mathrm{~min}$. at $20 \mathrm{fps}$.

FLAHERTY, Robert J. Nanook of the North. USA, 1922. b/w, silent film, 79 min.

ROUCH, Jean. La chasse au Lion à l'arc. 16/35 mm, couleur, $80 \mathrm{~min}$. França: Production Les Films de la Pléiade, 1965.

ROUCH, Jean. Les Maîtres Fous. 16/35 mm, couleur, 30 min. França: Production/ Distribution Les Films de la Pléiade, 1955.

ROUCH, Jean. Moi un noir. 16/35 mm, couleur, 73 min. França: Production Les Films de la Pléiade, 1959.

ROUCH, Jean. Petit à Petit. 16/35 mm, couleur, 90 min. França: Production/Distribution - Les Films de la Pléiade; Niger: Coproduction CNRS, CFE, 1965. 